\title{
Domesticidade e identidades de gênero na revista Casa \& Jardim (anos 1950 e 60)*
}

\author{
Marinês Ribeiro dos Santos**
}

\begin{abstract}
Resumo
A partir das imbricações entre os discursos sobre a domesticidade $e$ os modelos de identidade de gênero veiculados pela revista Casa \& Jardim, procuro discutir a participação das representações na constituição das subjetividades humanas. Entendidas como práticas discursivas, as representações influenciam por meio do estabelecimento de normas, padrões e valores que medeiam a compreensão do mundo e as condutas na vida social. Logo, as representações de feminilidades privilegiadas em Casa \& Jardim, longe de significarem o reflexo de uma suposta "natureza feminina", podem ser entendidas como tipos de subjetividades prescritas para suas leitoras.
\end{abstract}

Palavras-chave: Domesticidade, Relações de Gênero, Identidades, Subjetividades, Casa \& Jardim.

\footnotetext{
* Recebido para publicação em setembro de 2008, aceito em setembro de 2009.

** Doutora em Ciências Humanas pela UFSC e professora do Departamento Acadêmico de Desenho Industrial e do Programa de Pós-Graduação em Tecnologia da Universidade Tecnológica Federal do Paraná. ribeiro@utfpr.edu.br
}

cadernos pagu (36), janeiro-junho de 2011:257-282. 
Domesticidade e identidades de gênero na revista Casa \& Jardim

Domesticity and Gender Identities in Casa \& Jardim Magazine (1950s and 60s)

\begin{abstract}
In this paper, starting from the entwinement between gender identity models and the domesticity discourse present in the brazilian popular magazine Casa \& Jardim, I discuss the role of representations in the constitution of human subjectivities. Representations influence us as discursive practices by the establishment of norms, standards, and values, which mediate our understanding of the world and guide our conduct within the social milieu. The representations of femininity in Casa \& Jardim, disguised as reflections of a supposed feminine "nature", are indeed patterns of subjectivities prescribed by its authors and editors to their women readers.
\end{abstract}

Key Words: Domesticity, Gender Relations, Identities, Subjectivities, Casa \& Jardim. 
O objetivo deste artigo é explorar as relações de gênero na sua ligação com o espaço doméstico a partir da ótica das revistas de decoração. A investigação está centrada nos discursos veiculados pelo título Casa \& Jardim ${ }^{1}$ durante as décadas de 1950 e 1960. Lançada em 1952, a revista serviu como guia para o consumo doméstico de classe média durante uma época de urbanização $e$ industrialização aceleradas. Sua missão era, justamente, apresentar soluções capazes de conciliar a preservação dos valores tradicionais da família, ali entendida a partir do modelo nuclear e heterossexual, e a modernização do espaço das moradias. $\mathrm{O}$ que pretendo ressaltar são algumas das estratégias discursivas empregadas na construção de diferenças e assimetrias nas relações de gênero.

No período em estudo, os modelos de domesticidade veiculados em Casa \& Jardim tinham como premissa a existência de mundos masculino e feminino distintos. As representações de tipos de feminilidades privilegiadas no periódico insistiam na identificação das mulheres com o espaço doméstico e com as práticas de consumo voltadas para o lar. Vale ressaltar que, tradicionalmente, os significados dos conceitos "doméstico" e "consumo" são definidos em oposição à concepção de esfera pública e à noção de atividade produtiva, vistas como masculinas por excelência. Em contrapartida, a esfera doméstica e as práticas de consumo figuram como passivas, destinadas à reprodução (Hollows, 2000). Tal clivagem está na base do conceito de domesticidade cunhado ainda no século XIX, quando a casa deixou de ser vista como um espaço propício para a produção econômica. A identificação dos homens com o mundo público

1 Inicialmente concebido como "Casa e Jardim", a grafia do título mudou para "Casa \& Jardim" a partir de 1965. Este último formato foi mantido até hoje, uma vez que a revista continua em circulação. Neste artigo é adotada a grafia "Casa \& Jardim" como uma forma genérica para falar sobre a revista. Contudo, no caso das referências que tratam de volumes específicos, vou respeitar a grafia original. Além disso, nas citações de excertos de artigos e reportagens, vou reproduzir a convenção ortográfica em uso corrente. 
Domesticidade e identidades de gênero na revista Casa \& Jardim

veio acompanhada por discursos que justificavam a divisão do trabalho marcada por gênero a partir de diferenças "naturais" entre mulheres e homens (Heynen, 2005). Assim, os que "ganham o pão" passaram a contrastar com as que "tomam conta" da família e da casa.

Segundo Hilde Heynen (2005), os discursos sobre a domesticidade prescrevem uma série de normas acerca dos requisitos necessários para a vida em família, envolvendo desde preceitos sobre as necessidades das crianças, os cuidados com o corpo $e$ a saúde, as exigências de limpeza e higiene, a melhor forma de dividir o tempo entre o trabalho e o descanso, as maneiras apropriadas de preparar a comida e de cuidar das roupas, até a configuração do espaço da casa, o que inclui a decoração doméstica. Logo, a domesticidade pode ser entendida em termos de sistemas de normatizações, padrões de comportamento e arranjos espaciais, cujas repercussões sociais implicam em constelações de poder.

Nos discursos sobre a domesticidade, as relações de poder podem ser percebidas na naturalização de diferenças, na prescrição de papéis, na demarcação de limites e na instituição de assimetrias. Enquanto instrumento de ordenação do mundo, o discurso é parte constitutiva das relações sociais. Sendo assim, as representações de feminilidades em Casa \& Jardim podem ser entendidas como tipos de subjetividades prescritas para as suas leitoras, que, longe de serem o reflexo de uma suposta essência feminina, precisam ser problematizadas e historicizadas.

\section{A intermediação cultural em Casa e Jardim}

Como estratégia de leitura, vou caracterizar a revista Casa \& Jardim a partir do conceito de "mídia de estilo de vida". Segundo David Bell e Joanne Hollows (2005), esse tipo de mídia cumpre um papel importante na promoção e circulação de standards de gosto, de comportamentos de consumo e de modos de viver. Os principais assuntos abordados nas mídias de estilo de vida 
envolvem hábitos alimentares, receitas culinárias, cuidados com a saúde e com o corpo, auto-ajuda, moda, viagens, artigos de consumo e consumo cultural, bem como investimentos no local de moradia. Este último item abarca temas privilegiados em Casa \& Jardim, entre eles a decoração de interiores, a jardinagem $e$ as dicas do tipo "faça você mesmo". Contudo, vale lembrar que no período em estudo a revista também veiculava, de forma mais ou menos regular, reportagens que contemplavam os outros itens elencados. Sua contribuição na intermediação de valores $e$ comportamentos pode ser interpretada a partir de Jesús Martín-Barbero (2001) como socialmente produtiva, engendrando interpelações e discursos que, uma vez apropriados pelas pessoas mediante processos de reificação ou resistência, participam constitutivamente na trama da vida social.

Bell e Hollows (2005) consideram a produção das mídias de estilo de vida como uma prática social e cultural significativa, mediante a qual circulam valores que influenciam a constituição das identidades individuais e coletivas no interior da cultura de consumo contemporânea. São veículos que contribuem na produção, reprodução, reformulação ou dissolução de identificações sociais e culturais. A intermediação cultural desempenhada pelas/os realizadoras/os das mídias de estilo de vida assume um caráter de voz de autoridade capaz de interpretar e de traduzir, para parcelas particulares da população, conhecimentos e padrões de gosto relacionados às práticas cotidianas. Logo, as mídias de estilo de vida ocupam um lugar chave na promoção da diferenciação social.

Estou entendendo estilo de vida como

um conjunto mais ou menos integrado de práticas que um indivíduo abraça, não só porque essas práticas preenchem necessidades utilitárias, mas porque dão forma material a uma narrativa particular da auto-identidade (Giddens, 2002:79). 
Domesticidade e identidades de gênero na revista Casa \& Jardim

Ao forjar esta definição, o autor parte do pressuposto de que nas sociedades modernas, sob a influência de inúmeras formas de experiência mediada, a auto-identidade é um empreendimento ativo, organizado reflexivamente pelo sujeito e passível de revisões no decorrer do tempo. Nas palavras do autor, a auto-identidade consiste em

uma trajetória através das diferentes situações institucionais da modernidade por toda a duração do que se costumava chamar de "ciclo da vida", um termo que se aplica com maior precisão a contextos não-modernos que aos modernos. Cada um de nós não apenas "tem", mas vive uma biografia reflexivamente organizada em termos do fluxo de informações sociais e psicológicas sobre possíveis modos de vida. A modernidade é uma ordem póstradicional em que a pergunta "como devo viver?" tem tanto de ser respondida em decisões cotidianas sobre como comportar-se, o que vestir e o que comer - e muitas outras coisas - quanto ser interpretada no desdobrar temporal da auto-identidade (id.ib.:20-21, grifos e aspas no original).

No contexto da modernidade tardia, a ação de escolher emerge como um componente fundamental nas práticas cotidianas. Porém, na opinião de Giddens, isso não significa que todas as opções estão disponíveis para todas as pessoas, nem que as decisões são balizadas mediante o conhecimento da gama total de alternativas possíveis. Sendo assim, "a modernidade confronta o indivíduo com uma complexa variedade de escolhas e ao mesmo tempo oferece pouca ajuda sobre as opções que devem ser selecionadas" (id.ib.:79). É nesse sentido que funcionam as mídias de estilo de vida: como guias que ajudam a definir o que e como escolher dentro de um vasto rol de possibilidades que incluem produtos, serviços e também experiências. Elas oferecem oportunidades para a atualização pessoal, por meio de sugestões acerca de como as pessoas podem aprimorar suas vidas, tanto moral quanto esteticamente (Bell e Hollows, 2006). 
Volto à Casa \& Jardim tendo em vista esses parâmetros. Conforme já comentado anteriormente, a revista surgiu como guia para o consumo doméstico de classe média, apresentado sugestões capazes de conciliar a preservação dos valores tradicionais da família ${ }^{2}$ com a modernização do espaço doméstico. Num cenário de transformações sociais e culturais, as donas de casa podiam orientar suas escolhas quanto às práticas cotidianas a partir da opinião de especialistas. O contato com a voz da autoridade oportunizava a atualização dos modos de viver conforme o novo "espírito dos tempos". Com relação às identidades coletivas e à marcação de posições de classe, ao mesmo tempo em que Casa \& Jardim construía estilos de vida mediante práticas de consumo, o periódico também funcionava como um espaço de visibilidade para o estilo de vida da classe média. Um tipo de reportagem característico da revista consistia em apresentar imagens e comentários sobre a arquitetura e/ou a decoração de residências pertencentes às pessoas de "bom gosto" da sociedade brasileira.

No que concerne aos marcadores de gênero, quero estender um pouco a discussão sobre a identificação do consumo doméstico como uma prática feminina por excelência. Nesse sentido, Hollows (2000) indica mais uma oposição binária que precisa ser problematizada, a saber, a valorização da produção em detrimento do consumo. Conforme a autora, tanto o senso comum quanto a crítica social apresentam abordagens em que a produção aparece como uma atividade positiva e masculina, enquanto que o consumo é entendido como uma prática negativa e feminina. Visando ilustrar essa afirmação, Hollows escolheu como exemplo a teoria marxiana. Em contraste com a opinião de

2 As expectativas de conduta contempladas nas representações da família em Casa \& Jardim destacadas neste trabalho correspondem ao conjunto de convenções que regulava o relacionamento conjugal de classe média típico dos anos 1950. O que se veiculava como o tipo de comportamento feminino ideal mantinha o pressuposto antigo, porém continuamente atualizado, "de que as mulheres nascem para ser donas de casa esposas e mães” (Bassanezi, 1997:607). 
Domesticidade e identidades de gênero na revista Casa \& Jardim

Giddens apresentada anteriormente, para Marx o senso de autoidentidade é um produto que surge exclusivamente da relação humana com as atividades produtivas. Logo, o trabalho é valorado como uma prática fundamental, pois é a partir dele que podemos desenvolver nossa percepção acerca de quem somos. Vale lembrar que no contexto das sociedades capitalistas, em que as relações de poder são desiguais entre as classes sociais, as identidades produzidas mediante as atividades produtivas são identidades de classe. ${ }^{3}$ Uma vez que o consumo não é considerado como um trabalho, ele não pode servir como meio válido para a constituição de identidades "reais" (Hollows, 2000).

Dessa ideia decorrem críticas mais recentes, nas quais o enfraquecimento das identidade de classe deriva do fortalecimento de uma cultura de consumo responsável pela formação de consciências "falsas" ou "não autênticas". Segundo Hollows (2000), esse fenômeno é frequentemente associado a uma emasculação da sociedade. Ainda sobre os privilégios atribuídos à instância da produção, a autora também lembra que quando o processo produtivo é reconhecido como o foro responsável pela definição do sentido de textos, imagens e artefatos, a prática de consumir assume um caráter de aceitação passiva de significados anteriormente fixados. Sendo assim, voltando para a questão da separação entre as esferas, os homens figuram como aqueles que produzem e determinam os significados das coisas no mundo, enquanto que às mulheres resta consumir passivamente.

Conforme salienta Hollows (2000), o entendimento do consumo como "o outro" negativo da produção é uma concepção marcada por gênero. Julgamentos que classificam a atividade de consumo como impulsiva, trivial e passiva são comuns. Em contraposição, a produção geralmente é definida como uma atividade dignificante que demanda trabalho pesado ou

3 Na concepção de Marx, a dicotomia entre produção e consumo tem origem na oposição entre operários e capitalistas. A atribuição de características gendradas a estas duas categorias ocorreu posteriormente, mediante as várias interpretações que surgiram sobre sua obra. 
especializado, além de locus privilegiado para a organização política. Considerando o antagonismo entre as qualidades atribuídas ao masculino e ao feminino, o consumo fica alinhado aos atributos femininos. A autora ainda observa que essas características marcadas por gênero se repetem quando é necessário diferenciar os bons dos maus consumidores. $\mathrm{O}$ consumidor masculino racional funciona como a antítese da consumidora feminina alienada.

Em fevereiro de 1970, Casa \& Jardim publicou uma crônica de Simão Goldman na qual o autor faz uso desse contraste. $\mathrm{O}$ texto começa com uma dona de casa fazendo compras no supermercado. Goldman (1970) a descreve como alguém que não sabe ao certo o que é necessário levar para casa, de tão confusa diante da variedade de opções dispostas nas prateleiras. Hipnotizada pelas cores das embalagens e pelas lembranças dos apelos publicitários, ela nem percebe que encheu o carrinho de mercadorias. E, finalmente, quando vai ao caixa, não tem dinheiro suficiente para pagar a conta. Na sequência, o autor apresenta outra história enfocando o mesmo tema, só que desta vez protagonizada por um homem. O personagem é um alto executivo que trabalha doze horas por dia. Aos sábados, ele cultiva o hábito de ir ao supermercado para relaxar. Assim como a dona de casa da narrativa anterior, ele também se deixa seduzir pelas embalagens coloridas, porém de uma forma controlada $e$ prazerosa. Nos dois casos o consumo aparece como um momento de escapismo, contudo a ocasião é vivenciada de maneira muito diferente pelos dois personagens. Enquanto ela sai do supermercado confusa e ridicularizada, ele vai para casa feliz e orgulhoso das pequenas indulgências que carrega nos pacotes. Ele mantém o comando da situação e compra artigos supérfluos porque quer, ela é levada pelo turbilhão de ofertas e não tem sequer consciência do que adquiriu.

Hollows (2000) sugere que mitos negativos como esses retratados por Goldman (1970) dificultam a compreensão da atividade de consumo doméstico como uma forma de trabalho. 
Domesticidade e identidades de gênero na revista Casa \& Jardim

Tendo em vista as tarefas das donas de casa, ela defende que esse tipo de consumo deve ser percebido como uma prática produtiva, pois além de estar relacionado ao serviço da casa, também é um exercício interpretativo que oportuniza a participação das mulheres na produção de identidades de classe e de gênero. Nesse sentido, a mediação cultural de Casa \& Jardim é interessante para a análise, pois essas identidades são objetivadas no arranjo físico do espaço doméstico. Vale ressaltar que ao se apropriarem dos gostos e costumes veiculados pela revista, as donas de casa assumem, elas mesmas, a função de intermediárias culturais no universo de suas relações sociais (Gunn, 2005).

\section{Identidades e práticas discursivas}

Neste trabalho, estou assumindo que as identidades não são "naturais", "fixas" ou "imutáveis", mas construídas discursivamente. E isso implica em refutar a percepção desse conceito como algo essencialmente ligado ao sujeito, como se fosse uma espécie de núcleo estável e imutável capaz de singularizar os indivíduos ou, no caso das identidades de grupo, de reuni-los como um conjunto homogêneo. Tal núcleo faria parte da natureza da pessoa, permanecendo sempre igual ao longo do tempo. Segundo Stuart Hall (2000) essa é a forma como tradicionalmente o conceito de identidade vem sendo empregado. Porém, Hall também observa que a concepção tradicional de identidade não tem mais sustentação teórica se levarmos em conta as mudanças epistemológicas que ocorreram nas ciências sociais e humanas, principalmente a partir dos anos 1960, com a chamada "virada cultural". Esse termo faz referência a uma abordagem conceitual que privilegia a cultura como condição constitutiva da vida social e que desencadeou "uma revolução de atitudes em relação à linguagem" (Hall, 1997:27). A linguagem é entendida, nesse caso, de forma ampliada, como um termo geral para as práticas de representação, assumindo importância central na construção e circulação dos significados. Sendo assim, a 
linguagem passa a ser vista como uma prática capaz de constituir os fatos, e não apenas como algo que serve para descrevê-los.

Não se trata de questionar a existência de um mundo concreto ou das experiências objetivas, mas, isso sim, de ressaltar que os significados que construímos acerca desse mundo ou dessas experiências são sempre mediados discursivamente. Essa perspectiva nos possibilita questionar qualquer afirmação sobre uma suposta natureza essencial das coisas. Ou seja, estou assumindo que os significados não são intrínsecos às coisas, mas resultantes da articulação entre fatores materiais e sistemas culturais ou simbólicos. Conforme Hall (1997), os significados são construídos por meio da linguagem e das representações, que são práticas discursivas. O autor define discurso como

uma série de afirmações, em qualquer domínio, que fornece uma linguagem para se poder falar sobre um assunto e uma forma de produzir um tipo particular de conhecimento. $\mathrm{O}$ termo [discurso] refere-se tanto à produção de conhecimento através da linguagem e da representação, quanto ao modo como o conhecimento é institucionalizado, modelando práticas sociais e pondo novas práticas em funcionamento (Hall, 1997:33).

Logo, todas as práticas sociais, na medida em que necessitam de significados para funcionar, possuem um caráter discursivo. Nesses termos, reforça Hall, não é que tudo seja cultura, mas, isso sim,

que toda prática social depende e tem relação com o significado: consequentemente, que a cultura é uma das condições constitutivas de existência dessa prática, que toda prática social tem uma dimensão cultural (Hall, 1997:29).

Se os significados que atribuímos ao mundo social e também a nós mesmos são configurados por meio de práticas discursivas, as 
Domesticidade e identidades de gênero na revista Casa \& Jardim

representações adquirem importância central para a questão das identidades. Inserir o conceito de identidade dentro das discussões acerca da linguagem e da representação implica considerar uma série de pontos que o afastam da concepção tradicional, apresentada anteriormente. Conforme argumenta Joan Scott (1999:41), implica

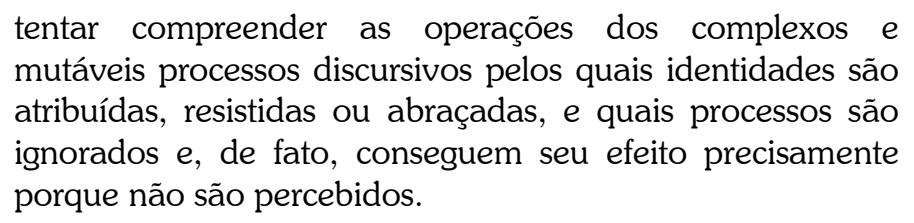

Mas como podemos entender esses processos de constituição das identidades? Hall observa que a ênfase na linguagem $e$ no significado tem contribuído para o apagamento da fronteira entre o social e o psíquico. Nas palavras do autor:

Utilizo o termo "identidade" para significar o ponto de encontro, o ponto de sutura, entre, por um lado, os discursos e as práticas que tentam nos "interpelar", nos falar ou nos convocar para que assumamos nossos lugares como os sujeitos sociais de discursos particulares $e$, por outro lado, os processos que produzem subjetividades, que nos constroem como sujeitos aos quais se pode "falar" (Hall, 2000:111-112, aspas e grifo no original).

Se assumimos determinadas posições de sujeito a partir da interpelação de representações específicas, isso implica no investimento dos sujeitos naquelas posições. Tal constatação introduz a ideia de identificação. As representações delimitam espaços, estabelecem fronteiras por meio das quais são marcadas as diferenças em relação a outras possibilidades de identificação. Em outras palavras, "as identidades são, pois, pontos de apego temporário às posições de sujeito que as práticas discursivas constroem para nós" (Hall, 2000:112). E esses pontos de apego são 
definidos de forma relacional, ou seja, a partir do que pode ser chamado de seu "exterior constitutivo". Logo, nas identidades, o que é externo constitui o que é interno: identidade e diferença são mutuamente determinadas. Embora seja comum pensarmos na identidade como o ponto de referência a partir do qual a diferença é definida, Tomaz Tadeu da Silva (2000) afirma que é a diferença que vem antes da identidade. Entendida como o próprio ato de diferenciação, a diferença se apresenta como o processo capaz de produzir nossas noções tanto de identidade quanto de diferença.

Sendo assim, aqui cabem alguns exemplos acerca de como as identidades de gênero em Casa \& Jardim são tanto estruturadas a partir da marcação de diferenças entre os sexos, quanto operam no sentido de afirmar esses contrastes na forma de oposições binárias. No que tange à decoração de interiores, a revista trabalha com a noção de que a personalidade das pessoas está interligada aos ambientes que elas habitam. Logo, o arranjo dos espaços domésticos serve como meio para o estabelecimento de identidades de gênero. $\mathrm{Na}$ reportagem "Onde dormem as crianças", as leitoras interessadas em decorar os quartos de suas/seus filhas/os são aconselhadas a balizar suas decisões conforme o sexo, a idade, os hábitos e as preferências de cada criança. Contudo, a ênfase nos aspectos particulares é perpassada por generalizações. As personalidades relacionadas à variável sexo são interpretadas a partir da clivagem masculino/feminino, cujas respectivas características são assumidas como naturais $e$ universais. Sendo assim,

naturalmente que o quarto do garotinho em nada deve ser semelhante ao da menina. Um menino que já se sente um homenzinho, por certo não gostará, também, de ver o seu quarto decorado infantilmente. Cada personalidade exige uma solução. Essa regra é válida tanto para adultos como para crianças (Casa \& Jardim, março de 1966:20). 
Domesticidade e identidades de gênero na revista Casa \& Jardim

Em outra matéria sobre quartos para adolescentes, o texto apresenta a seguinte versão do que seriam as diferenças entre personalidades masculinas e femininas traduzidas na decoração de ambientes:

Um quarto para rapaz precisa ser diagramado a proporcionar-lhe, também, um agradável ambiente de estudo. Móveis singelos, onde apenas a textura da madeira representa papel importante, e prateleiras para livros, as miniaturas, as peças de coleção. O detalhe pode e deve ser coisa muito pessoal - aquilo que se guardou porque se achou interessante, o velho violão que acompanhava as serenatas do papai, mas que hoje só conhece os acordes da bossa-nova, uma página bonita arrancada da folhinha, um cartaz, um veleiro, um mundo de coisas mais (Casa \& Jardim, outubro de 1966:54-56).

Dispensando muitas ornamentações além dos objetos de escolha pessoal que servem para personalizar o ambiente, $\mathrm{o}$ quarto masculino é apresentado como um espaço que deve traduzir equilíbrio entre repouso e estudo. Por outro lado,

já a decoração do quarto da mocinha se presta a mil e uma fantasias. Se os móveis são mais leves, leves também são os tecidos usados para as colchas e cortinas, que tanto podem ser lisas, ornadas de passamanaria, ou estampadas.

Paredes em tons pastel ou alegremente desenhadas em fundos de papel criam a atmosfera própria para a adolescente que tem sonhos côr-de-rosa. Também ela tem suas preferências em matérias de detalhe: bebês rechonchudos - reminiscências da infância - bibelôs, um violão de estimação, flôres em buquês ou em gravuras emolduradas de dourado e vidros de perfume compõem o seu mundo de doce fantasia (Casa \& Jardim, outubro de 1966:57). 
Seguindo essa mesma linha, a edição de setembro de 1965 alega que homens e mulheres têm concepções diferentes sobre a decoração de quartos de dormir. O homem imagina o dormitório como "um refúgio agradável, mobiliado com móveis severos e confortáveis, em côres discretas. Muitos livros, uma mesa de bom tamanho e uma poltrona onde possa ler em paz". A mulher, por sua vez, prefere um quarto "revestido de um pouco da frivolidade que lhe é inata, com côres garridas, flôres sempre frescas, móveis leves e elegantes" (Casa \& Jardim, setembro de 1965:33).

O jogo de oposições também foi empregado na publicação de março de 1959. A matéria intitulada "Aqui dorme um homem" apresenta duas sugestões de decoração para quartos de dormir masculinos. Enquanto em uma delas são permitidos alguns "caprichos" como estatuetas e quadros, a outra é definida como espartana, onde predominam linhas retas e formas geométricas. A imagem masculina é definida como racional, organizada $e$ metódica: "bem se pode imaginar que em ambos os dormitórios, as pilhas de camisas estão em cuidadosa ordem, as meias em filas alinhadas conforme suas côres, etc." (Casa e Jardim, março de 1959:47). Em contraste, na matéria "Aqui dorme uma senhora" (Casa e Jardim, março de 1959:48), o ambiente ilustrado "exprime tôda a feminilidade. É um clima, um estado de alma, um mundo secreto, do qual a senhora se orgulha e que deixa bater seu coração mais rápido". No caso feminino, a emoção e o mundo subjetivo são ressaltados. Segundo o texto, nesse quarto, até o trivial adquire um caráter amável e resplandecente. $\mathrm{O}$ efeito causado pela decoração que privilegia os motivos florais é "alegre como um jardim".

Ao destacar esses exemplos, não pretendo afirmar que todas as/os leitoras/es de Casa \& Jardim ficavam convencidos ou satisfeitos com essas representações. Contudo, elas consistiam em discursos que divulgavam expectativas sociais capazes de influenciar seus julgamentos e escolhas. A constituição de uma identidade depende da negociação entre diferentes representações que coexistem e, muitas vezes, competem entre si. As pessoas 
Domesticidade e identidades de gênero na revista Casa \& Jardim

podem se identificar mais com umas e menos com outras dessas representações. Algumas pessoas também podem não se identificar com nenhuma delas, o que, em determinadas circunstâncias, leva à definição de um novo foco de identificação, alternativo aos anteriormente estabelecidos. Segundo Hall (1997), mesmo que as pessoas não se sintam plenamente representadas por nenhum dos discursos, elas tendem a se sentir mais atraídas por alguns deles. Isso significa que elas começaram a investir em uma determinada representação, começam a se identificar com ela e a adotá-la como uma posição-de-sujeito a partir da qual podem construir auto-representações. Nas palavras do autor:

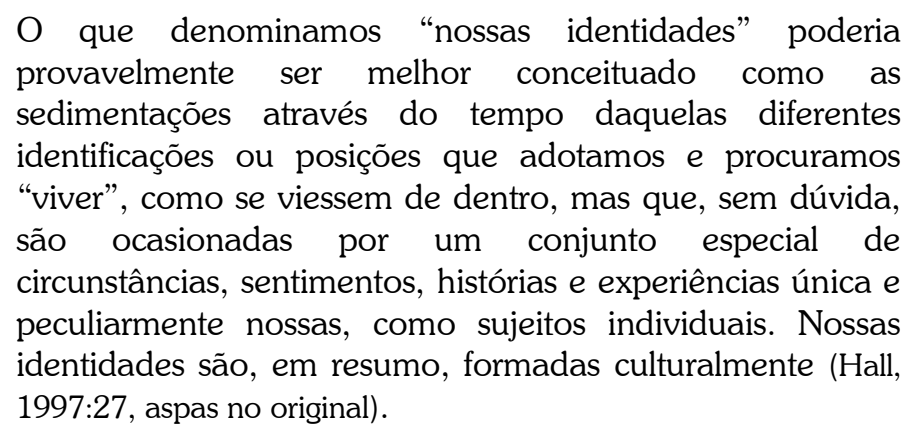

Nesse contexto, a cultura é definida como a somatória de sistemas de classificação $e$ de formações discursivas às quais recorremos, através da linguagem, para dar significado às coisas. Hall (1997) enfatiza o papel central ocupado pela cultura na constituição das subjetividades humanas. Conforme Kathryn Woodward (2000), subjetividade é um termo que sugere a compreensão que temos acerca de nós próprios. Ele envolve pensamentos e emoções, conscientes $e$ inconscientes, que constituem a concepção que construímos sobre quem somos. Porém, argumenta Woodward (2000:55), "vivemos nossa subjetividade em um contexto social no qual a linguagem $e$ a cultura dão significado à experiência que temos de nós mesmos e no qual adotamos uma identidade". Logo, as identidades sociais 
que assumimos são perpassadas pelas representações e, portanto, situam-se no domínio da cultura:

Elas são o resultado de um processo de identificação que permite que nos posicionemos no interior das definições que os discursos culturais (exteriores) fornecem ou que nos subjetivemos (dentro deles). Nossas chamadas subjetividades são, então, produzidas parcialmente de modo discursivo e dialógico (Woodward, 2000:26-27).

O caráter discursivo das práticas sociais e sua influência na constituição de subjetividades nos leva à questão da regulação de valores, condutas e comportamentos através da cultura. Para Hall (1997), a dimensão cultural ocupa uma posição privilegiada nos processos de regulação social, implicando o reconhecimento de que existe uma relação estreita entre cultura e poder. Os arranjos de poder discursivos e simbólicos, por meio da sua capacidade de modelar e controlar a cultura, exercem influência sobre o mundo social e sobre as individualidades, pois "toda a nossa conduta $e$ todas as nossas ações são moldadas, influenciadas e, desta forma, reguladas normativamente pelos significados culturais" (Hall, 1997:41).

Vejamos como as representações de Casa \& Jardim podem operar no sentido da normatização de expectativas e condutas quanto ao gênero. Além da diferenciação na escolha dos elementos decorativos, já abordada anteriormente, os ambientes da casa também são associados ao masculino ou ao feminino a partir das funções que lhes são destinadas. O escritório é insistentemente classificado como um cômodo masculino. É lá que o dono da casa pode trabalhar com calma, "sem interrupções e barulhos, venham de que lado vierem". Na concepção da revista, a decoração dessa peça não precisa lembrar um escritório, mas, "deve apresentar, ao lado de sua utilidade, um caráter pessoal, que faça o homem sentir-se bem e lhe transmita o fluido certo para resolver seus problemas" (Casa e Jardim, março de 1959:25). 
Domesticidade e identidades de gênero na revista Casa \& Jardim

Em março de 1965, na reportagem "Só para homens" o escritório aparece como um espaço reservado para os maridos que querem trabalhar, dedicar-se a um passatempo, ou mesmo relaxar no ambiente doméstico. Diz o texto:

\begin{abstract}
uma boa esposa sabe que seu marido, ao voltar do trabalho, precisa encontrar um ambiente confortável $e$ acolhedor. Esta é a razão pela qual ela reserva um lugar especial para "êle". Os homens adoram possuir um canto só para si mesmos, onde reinem sozinhos entre livros, discos e outros "hobbies'". E a psicologia tem demonstrado o quanto isto é importante para a paz da família (Casa e Jardim, março de 1965:21).
\end{abstract}

Embora sem relacionar esse fato com a paz familiar, Casa \& Jardim também considerou a possibilidade das donas de casa desejarem um "cantinho" só para elas (Casa \& Jardim, julho de 1966:78-80). A edição de abril de 1963 apresentou uma série de pequenos escritórios que podiam servir tanto aos chefes de família atarefados que necessitam dar continuidade ao trabalho na própria residência, quanto às donas de casa interessadas em um recanto particular destinado às atividades de costura, tricô ou outros trabalhos artísticos (Casa e Jardim, abril de 1963:32-34). Em outubro de 1965, foi publicada outra reportagem sobre escritórios femininos, enfocando esse ambiente como o lugar ideal para a administração da rotina doméstica. Ali, munidas de livros de receitas e da lista de fornecedores, as donas de casa estariam equipadas para planejar as compras semanais e o cardápio diário (Casa \& Jardim, outubro de 1965:61). A reportagem "Aquêle canto difícil" (Casa \& Jardim, janeiro de 1969:49-50) indica soluções para conjugar o escritório do marido e o quarto de costura da esposa em um mesmo cômodo. Como podemos observar, a ideia de escritório feminino nesses textos está ligada à rotina doméstica e à esfera privada, enquanto que o escritório masculino serve como 
um espaço de extensão ou refúgio da esfera pública dentro de casa.

Outro texto, publicado em abril de 1967, define ocupações diferenciadas para o mesmo cômodo da habitação, estabelecendo expectativas femininas e masculinas distintas. A reportagem discorre sobre as vantagens de uma sala íntima na casa ou apartamento. Durante o dia, a sala íntima pode servir às mulheres que não trabalham fora como o lugar ideal tanto para costurar, tricotar, bordar e organizar o livro de receitas, quanto para ler, ver televisão ou conversar com as amigas. Contudo, à noite,

enquanto no resto da casa ainda há movimento, o homem encontra aí o seu mundo. Para ler os jornais, o trabalho intelectual, para ouvir música entre uma cerveja gelada e as notícias da TV é o melhor ambiente (Casa \& Jardim, abril de 1967:37).

Além dos interesses diversos, que contrastam habilidades manuais com intelectuais e distração com informação, fica implícita a responsabilidade das mulheres para com os afazeres domésticos e o cuidado dos filhos. Representações como essas ajudam a manter a oposição entre as esferas pública e privada e marcam a identificação do masculino e do feminino com cada uma delas.

Como práticas culturais, as representações nos regulam por meio do estabelecimento de normas, padrões e valores que dirigem nossa compreensão do mundo e nossas condutas na vida social. O sistema de valores dominante nas sociedades nos influencia normativamente no sentido de guiar os significados que atribuímos às práticas sociais. É nesse sentido que Scott (1999) chama a atenção para a importância de considerarmos as relações entre discurso, cognição e o que entendemos por "realidade". As posições-de-sujeito que assumimos perante os sistemas de valores são fundamentais para os significados que atribuímos às nossas experiências de vida $e$, consequentemente, às nossas próprias subjetividades. Para Scott, esses processos de identificação devem 
Domesticidade e identidades de gênero na revista Casa \& Jardim

ser historicizados. Ela compreende os processos de constituição de identidades como eventos históricos que precisam ser explicados. Isso implica pensar sobre os posicionamentos assumidos pelos sujeitos como um efeito da dimensão discursiva envolvida nas relações de poder.

Porém, a autora ressalta que não devemos pensar nas identidades como resultado de um determinismo linguístico. Ou seja, é necessário considerar o caráter produtivo dos discursos, porém os sujeitos não devem ser destituídos da sua capacidade de agenciamento. Scott (ib.:42) aponta que "sujeitos são constituídos discursivamente, mas existem conflitos entre sistemas discursivos, contradições dentro de cada um deles, múltiplos sentidos possíveis para os conceitos que usam". Logo, embora sujeitados por condições determinadas pelas práticas sociais e pelos sistemas de significação, os sujeitos ainda preservam a capacidade, mesmo que limitada, de fazer escolhas. As identidades se formam na imbricação entre o social e o pessoal e esse processo é sempre variável $e$ histórico. Para Scott, as identidades são tanto interpretação em si, quanto algo que requer interpretação.

Sendo assim, no caso específico das identidades de gênero, vou assumir a interpretação de Judith Butler (2003) acerca do caráter construído da diferença entre os sexos. A crítica desta autora quanto às oposições binárias engloba o par sexo/gênero, que supõe o primeiro como natural e o segundo como produto da cultura. Para ela, a noção de sexo como algo natural, ou prédiscursivo, pode ser entendida como um efeito do aparato cultural designado por gênero. Nas palavras da autora:

O gênero não deve ser meramente concebido como a inscrição cultural de significado num sexo previamente dado (uma concepção jurídica); tem de designar também o aparato mesmo de produção mediante o qual os próprios sexos são estabelecidos. Resulta daí que o gênero não está para a cultura como o sexo para a natureza; ele é o meio discursivo/cultural pelo qual "a natureza sexuada" ou um "sexo natural" é produzido e estabelecido como "pré- 
discursivo", anterior à cultura, uma superfície politicamente neutra sobre a qual age a cultura (Butler, 2003:25).

Com essa concepção, Butler (ib.:185) questiona as categorias do "sexo verdadeiro, do gênero distinto e da sexualidade específica". Para ela, o gênero é constituído normativamente por meio de discursos e práticas reguladoras que inscrevem o sexo no corpo. Esses discursos e práticas servem como referência para o estabelecimento de "códigos específicos de coerência cultural" que naturalizam os limites impostos para mulheres $e$ homens (id.ib.:188). Assim, uma ilusão de estabilidade de gênero é instituída com a incorporação das normas sociais. Logo, a norma hegemônica da heterossexualidade ligada à reprodução exclui do domínio do inteligível outras possibilidades de desejo. Partindo da ideia foucaultiana de que as normas produzem os sujeitos que regulam, Butler entende que a incorporação das normas de gênero ocorre pela repetição contínua de atos performativos.

Em outras palavras, as identificações de gênero se constroem no tempo, são incorporações postas em atos que se traduzem na estilização dos corpos. Segundo a autora, a identidade de gênero pode ser reconcebida como

uma história pessoal/cultural de significados recebidos, sujeitos a um conjunto de práticas imitativas que se referem lateralmente a outras imitações e que, em conjunto, constroem a ilusão de um gênero primário $e$ interno (id.ib.:197).

Uma vez que a subjetividade de gênero não é ontológica, mas, isso sim, uma construção mediante normalizações, os padrões impostos pela heterossexualidade compulsória - que implicam na diferença binária entre os sexos - necessitam de repetição contínua para afirmarem-se como hegemônicos. Nesse sentido, as revistas de decoração que fazem parte deste trabalho podem ser interpretadas como veículos de representações que contribuíam para a reiteração das normas hegemônicas na vida social. 
Domesticidade e identidades de gênero na revista Casa \& Jardim

\section{Considerações finais}

De acordo com os exemplos destacados dentro do recorte temporal em estudo, podemos perceber que Casa \& Jardim organizava seu discurso acerca das identidades de gênero a partir de oposições binárias. As ditas personalidades femininas $e$ masculinas aparecem contrastadas de acordo com a dicotomia tradicional, em que o mundo subjetivo de fantasias românticas é a antítese dos interesses objetivos voltados para a esfera pública. Essas diferenças, apresentadas como "naturais" e "universais", são materializadas tanto nas representações de decoração dos ambientes quanto nas representações dos usos que se fazem deles. Como práticas culturais, as representações nos influenciam por meio do estabelecimento de normas, padrões e valores que medeiam nossa compreensão do mundo e nossas condutas na vida social. As posições-de-sujeito que assumimos perante os sistemas de valores são fundamentais para os significados que atribuímos às nossas experiências de vida e, consequentemente, às nossas próprias subjetividades. Nesse sentido, como uma resposta ao processo de modernização da sociedade, as representações de identidades de gênero em Casa \& Jardim operaram como discursos que, somados a outros tantos, contribuíram para a naturalização das relações tradicionais de gênero no entendimento comum dos significados simbólicos que regulavam as práticas cotidianas.

Vale lembrar que a partir dos anos 1960, o questionamento da clivagem entre as esferas pública e privada foi uma das questões centrais na agenda do feminismo de segunda onda. ${ }^{4}$ Mediante a máxima "o pessoal é político" os discursos feministas

4 O movimento feminista de "segunda onda" se desenvolveu após a segunda guerra mundial, dando prioridade às lutas pelo direito ao corpo e ao prazer, bem como contra a subordinação das mulheres pelo poder masculino. Certamente essa vertente do feminismo é tributária da "primeira onda", deflagrada ainda no século XIX e centrada na reivindicação de direitos políticos, sociais e econômicos (Pedro, 2005). 
buscavam explicitar as interligações entre as experiências pessoais $e$ as condições de subordinação promovidas pelas relações sociais de poder, denunciando que a vida social é inseparável da particular (Campagnoli, 2005). A defesa de que o pessoal também é político servia não apenas como base para sustentar o desejo de evitar que questões relativas à subordinação na esfera doméstica ou à violência sexual ficassem reféns dos julgamentos morais particulares, mas também indicava a necessidade da reconstrução do sujeito feminino frente à sociedade. Como afirma Mabel Campagnoli (2005), nesse contexto o âmbito do privado representava tanto um projeto quanto um espaço de luta política.

Para Joana Maria Pedro (2008), estava premente a busca por novas "imagens de si". As mulheres envolvidas com as lutas feministas almejavam construir identidades diferentes daquelas que lhes havia reservado a cultura androcêntrica, no interior da qual se sentiam depreciadas. A "família tradicional" foi alvo de críticas, entendida como um reduto de hipocrisia e opressão. Interessadas na configuração de alternativas para as relações conjugais, as demandas feministas abarcavam questões como a paridade na remuneração e nas oportunidades de trabalho disponíveis aos homens; o direito ao corpo e à sexualidade; e a reconfiguração das representações de tipos de feminilidades, visando libertar as mulheres do comprometimento necessário com a figura da "rainha do lar".

É interessante observar que durante os primeiros anos da década de 1970, referências às reivindicações feministas foram incorporadas ao repertório dos discursos veiculados em Casa \& Jardim, sobretudo nos anúncios publicitários, servindo como recurso retórico para a atualização das representações da dona de casa. ${ }^{5}$ Contudo, nesse procedimento de atualização, a apropriação de termos usados nos discursos feministas e o reconhecimento de modificações nos comportamentos das mulheres na vida social servem como artifícios para a afirmação da ligação das mulheres

5 Para uma abordagem mais aprofundada desta questão, ver: Santos, 2010. 
Domesticidade e identidades de gênero na revista Casa \& Jardim

com universo doméstico. Nas apropriações em questão, tais discursos são usados como um "verniz de modernidade" para práticas tradicionalmente definidas como femininas, por meio do estabelecimento de pontes com as preocupações feministas.

Dessa forma, ao mesmo tempo em que a arenga acerca da clivagem entre público e privado persiste, a imagem da dona de casa é atualizada mediante a sua identificação, ainda que superficial e periférica, com os interesses femininos de vanguarda. Conforme nos mostra Tania Navarro Swain (2001), esse tipo de artifício continua em uso em diversas revistas direcionadas para públicos femininos, operando como mecanismo de reificação das normas hegemônicas que insistem em naturalizar tipos de subjetividades que são construídos para suas leitoras.

\section{Referências bibliográficas}

BASSANEZI, Carla. Mulheres dos anos dourados. In: Del PRIORE, Mary (org.) História das Mulheres no Brasil. São Paulo, Contexto, 1997, pp.607-639.

BELL, David e Hollows, Joanne (eds.) Making sense of ordinary lifestiles. In: Ordinary Lifestiles: popular midia, consumption and taste. UK, Berkshire, Open University Press, 2005, pp.1-18.

BELl, David e Hollows, Joanne (eds.) Towards a history of lifestile. In: Historicising Lifestile: mediating taste, consumption and identity from the 1900s to 1970s. UK, Hampshire, Ashgate Publishing Limited, 2006, pp.1-20.

BUTLER, Judith. Problemas de Gênero: feminismo e subversão da identidade. Rio de Janeiro, Civilização Brasileira, 2003.

CAMPAGNOLI, Mabel Alicia. El feminismo es un humanismo: la década del 70 y "lo personal es político". In: ANDUJAR, Andrea et alii. Historia, genero y política em los '70. Buenos Aires, Feminaria Editora, 2005, pp.154-168.

GIDDENS, Anthony. Modernidade e Identidade. Rio de Janeiro, Jorge Zahar, 2002. 
GunN, Simon. Translating Bourdieu: cultural capital and the English middle class in historical perpective. The British Journal of Sociology, vol. 56, issue 1, UK, London, 2005, pp.49-64.

HALL, Stuart. A centralidade da cultura: notas sobre as revoluções culturais do nosso tempo. Educação e Realidade, vol. 22, n 2, Porto Alegre, jul/dez 1997, pp.15-46.

HALL, Stuart. Quem precisa de identidade? In: SILVA, Tomaz Tadeu da (org.) Identidade e Diferença: a perspectiva dos estudos culturais. Petrópolis, RJ, Vozes, 2000, pp.103-133.

HEYNEN, Hilde. Modernity and Domesticity: tensions and contradictions. In: HEYNEN, Hilde e BAYDAR, Gülsüm (eds.) Negotiating Domesticity: spatial productions of gender in modern architecture. UK, Abingdon, Routledge, 2005, pp.1-29.

Hollows, Joanne. Feminism, Femininity and Popular Culture. Manchester-UK, Manchester University Press, 2000.

MARTín-BARBERO, Jesús. Dos meios às mediações: comunicação, cultura e hegemonia. Rio de Janeiro, Editora da Universidade Federal do Rio de Janeiro, 2001.

PEDRO, Joana Maria. Traduzindo o debate: o uso da categoria gênero na pesquisa histórica. História, vol. 24 (1), São Paulo, UNESP, 2005, pp.77-98.

PEDRO, Joana Maria. Uma Nova Imagem de Si: identidades em Construção. In: RAMOS, Alcides Freira; PATRIOTA, Rosangela; PESAVENTO, Sandra Jataí. (orgs.) Imagens na História: objetos de história cultural. Rio de Janeiro, Hucitec, 2008, pp.415-429.

ScoTT, Joan. Experiência. In: SILVA, Alcione Leite da; LAGO, Mara Coelho de Souza, e RAMOS, Tânia Regina Oliveira. (orgs.) Falas de Gênero: teorias, análises, leituras. Florianópolis, Ed. das Mulheres, 1999, pp.21-55.

SANTOS, Marinês Ribeiro. O design Pop no Brasil dos anos 1970: domesticidades e relações de gênero na revista Casa \& Jardim. Tese de Doutorado em Ciências Humanas, UFSC, 2010.

SILVA, Tomaz Tadeu da. A produção social da identidade e da diferença. 
Domesticidade e identidades de gênero na revista Casa \& Jardim

In: SILVA, Tomaz Tadeu da. (org.) Identidade e Diferença: a perspectiva dos estudos culturais. Petrópolis-RJ, Vozes, 2000, pp. 73102.

SwAIN, Tania Navarro. Feminismo e recortes do tempo presente: mulheres em revistas "femininas". São Paulo em Perspectiva, 15 (3), São Paulo, Fundação SEADE, 2001, pp.67-81.

WOODWARD, Kathryn. Identidade e diferença: uma introdução teórica $e$ conceitual. In: SILVA, Tomaz Tadeu da (org.) Identidade e Diferença: a perspectiva dos estudos culturais. Petrópolis-RJ, Vozes, 2000, pp.7-72. 